\title{
Epiphytic ferns and bryophytes of Tasmanian tree-ferns: A comparison of diversity and composition between two host species
}

\author{
NINA R. ROBERTS, PATRICK J. DALTON` AND GREGORY J. JORDAN \\ School of Plant Science, University of Tasmania, Locked Bag 55, Hobart, Tasmania 7001, Australia \\ (Email: P.F.Dalton@utas.edu.au)
}

\begin{abstract}
Ferns, bryophytes and lichens are the most diverse groups of plants in wet forests in south-eastern Australia. However, management of this diversity is limited by a lack of ecological knowledge of these groups and the difficulty in identifying species for non-experts. These problems may be alleviated by the identification and characterization of suitable proxies for this diversity. Epiphytic substrates are potential proxies. To evaluate the significance of some epiphytic substrates, fern and bryophyte assemblages on a common tree-fern species, Dicksonia antarctica (soft tree-fern), were compared with those on a rare species, Cyathea cunninghamii (slender tree-fern), in eastern Tasmania, Australia. A total of $97 \mathrm{fern}$ and bryophyte species were recorded on D. antarctica from 120 trunks at 10 sites, and 64 species on C. cunninghamii from 39 trunks at four of these sites. The trunks of C. cunninghamii generally supported fewer species than D. antarctica, but two mosses (particularly Hymenodon pilifer) and one liverwort showed significant associations with this host. Several other bryophytes and epiphytic ferns showed an affinity for the trunks of D. antarctica. Species assemblages differed significantly between both sites and hosts, and the differences between hosts varied significantly among sites. The exceptionally high epiphytic diversity associated with $D$. antarctica suggests that it plays an important ecological role in Tasmanian forests. Evidently C. cunninghamii also supports a diverse suite of epiphytes, including at least one specialist species.
\end{abstract}

Key words: Cyathea, Dicksonia, liverworts, microhabitat, mosses, substrate preferences, tree-ferns.

\section{INTRODUCTION}

For management purposes and in most plant ecological studies, forest communities are typically defined using the composition of vascular plants in the canopy and under-storey vegetation. However a high portion of floristic diversity may exist at a much smaller scale, selecting and partitioning microhabitats according to substrate and microclimate. For example, bryophyte species often outnumber vascular species by a factor of four or five in the wet sclerophyll forests and cool temperate rainforests of the island of Tasmania, Australia (Jarman \& Kantvilas 1994; Pharo \& Blanks 2000). Also, an area of forest with a relatively homogenous vascular flora is likely to contain a high degree of variation among bryophytes, lichens, fungi and ferns (often collectively referred to as cryptogams) (Jarman \& Kantvilas 1994; Pharo \& Blanks 2000).

The ecology and habitat requirements of cryptogam species are generally poorly understood, largely because field identification of many species is time consuming for experts, and impossible for non-experts. However, such knowledge is becoming important for

${ }^{\star}$ Corresponding author.

Accepted for publication April 2004 biodiversity-protection measures in forest management because cryptogams are abundant in wet forests exploited heavily for forestry. One option is to establish appropriate surrogates for cryptogam species composition and diversity. Substrate may be such a surrogate, and it continues to attract attention (Pharo \& Blanks 2000; Pharo \& Beattie 2002; Turner 2003). Epiphytic substrates often support diverse cryptogamic floras and provide unique microhabitats. The host species is one variable by which to characterize these microhabitats, and many tree species support distinctive epiphytic assemblages (Scott 1970; Slack 1976; Piippo 1982; Wolf 1994). It follows that hosts offering especially distinctive substrates are most likely to support distinctive epiphytic assemblages and specialist species. Tree-ferns, collectively, are such hosts.

Both tropical and temperate species of tree-fern provide favourable habitat for many epiphytic bryophyte and fern species (Pócs 1982; Hassall \& Kirkpatrick 1985; Page \& Brownsey 1986; Heatwole 1993; Medeiros et al. 1993; Ough \& Murphy 1996; Moran et al. 2003). Tree-ferns do not undergo secondary growth, and therefore do not possess wood or bark. Instead, structural support is provided by a dense mass of intertwined adventitious roots that surround the stem (often referred to as a root mantle). The 
resulting 'trunk' (technically referred to as a caudex) of the fern offers a substrate quite distinct from seedplant trunks. Texture and other trunk attributes also vary among tree-fern species.

Beever (1984) found that Cyathea medullaris, Cyathea dealbata and Dicksonia squarrosa in New Zealand each hosted a characteristic community of moss epiphytes. This was attributed to differences in the texture of the trunk. Similarly, Ashton (1986) suggested that the greater luxuriance of epiphytes on the trunks of Dicksonia antarctica than on Cyathea australis in wet eucalypt forest in Victoria, Australia, was due to the thicker, moister and more finely textured root mantle of D. antarctica. Dicksonia antarctica trunks had approximately twice the water-holding capacity of C. australis trunks (Ashton 1986).

Tasmania, situated at approximately 42 degrees south, is an island with a cool temperate climate and some large areas of tall wet forest that provide a multitude of humid microhabitats occupied by ferns and bryophytes. Epiphytic substrates, including trunks of two species of tree fern, are particularly well utilized in these forests.

Dicksonia antarctica (commonly known as soft treefern or man-fern) is the most abundant and widespread species of tree-fern in Tasmania. It dominates the understorey vegetation in many wet forests (Busby \& Brown 1994; DPIWE 2001), and often extends into dry sclerophyll forest along streams. It ranges from sea level to approximately $900 \mathrm{~m}$ elevation (Garrett 1996).

Cyathea cunninghamii is present in Tasmania in very localized populations on the banks of low altitude streams (Garrett 1996), and often reaches heights of around $10 \mathrm{~m}$. Its trunk is narrow (approx. $12-16 \mathrm{~cm}$ diameter), with visible, persistent frond bases, except in the lower few tens of centimetres of trunks of over $5 \mathrm{~m}$ in height, which become enveloped by a mantle of adventitious roots. This contrasts with the thick, soft and fibrous mat of all but the smallest D. antarctica trunks.

Two other species of tree-fern occur in Tasmania, C. australis and Todea barbara, as well as a putative hybrid between C. australis and C. cunninghamii (C. X marcescens) (McCarthy \& Orchard 1998). These species appear to host relatively fewer epiphytes, perhaps because they occupy drier habitats.

This study assesses the diversity of bryophyte and fern epiphytes on tree-fern trunks in south-eastern Tasmania, to contribute to the evaluation of a substrate-as-surrogate approach to management of diversity. Specifically, it tests the hypotheses that the substrates provided by the tree-ferns C. cunninghamii and D. antarctica differ significantly in (i) epiphytic diversity (at the regional, site and trunk scales); (ii) relative frequencies of individual epiphytic species, and (iii) epiphytic species assemblages.
In addition to testing these hypotheses relating to host differences, the significance of site variation in influencing epiphytic assemblages on these tree-ferns was assessed so as to evaluate the appropriateness of host-presence as a surrogate for epiphytic species presence.

\section{METHODS}

\section{Study sites}

Floristic data on tree-fern epiphytes were collected from 10 sites in eastern and south-eastern Tasmania (Fig. 1; Table 1). Dicksonia antarctica was moderately to highly abundant at all sites. Four sites contained Cyathea cunninghamii. The choice of the remaining six sites aimed for an even geographical spread throughout the region. They were not restricted by vegetation type, except that they needed to contain D. antarctica more than $2 \mathrm{~m}$ tall. Sites with recent large-scale disturbance were avoided, although several sites were selectively logged perhaps 50-100 years ago. The size and shape of the areas in which sampling occurred were defined partly by the homogeneity of the forest in each location. The sampled trunks were generally spaced at less than $10 \mathrm{~m}$ apart and the study areas were no more than $100 \mathrm{~m}^{2}$ in area, however, riparian sites were necessarily long and narrow so as to remain within the same forest-type.

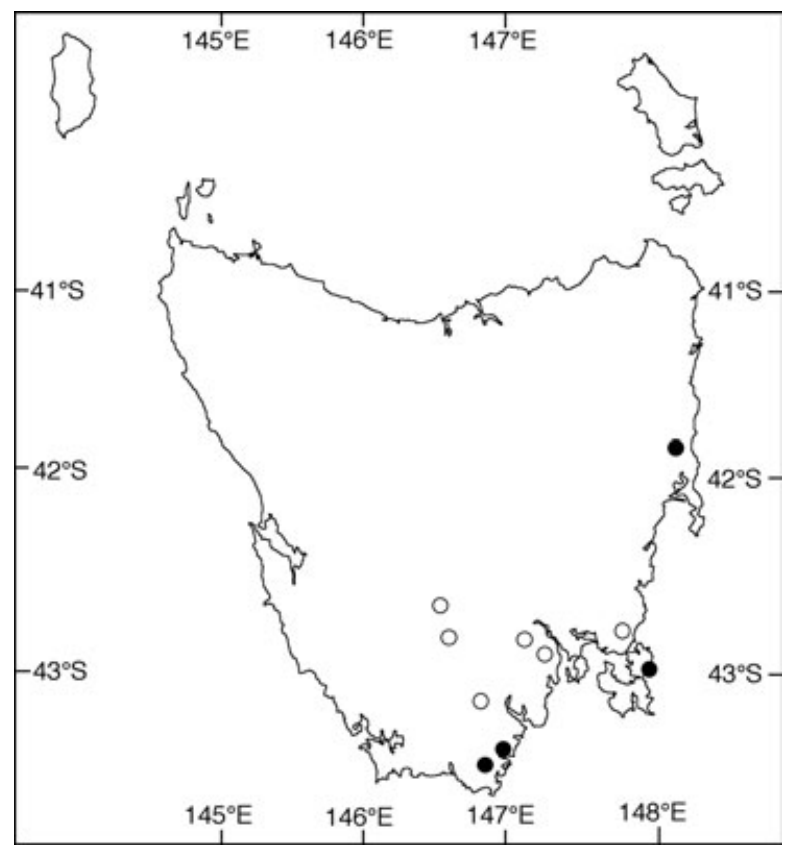

Fig. 1. Tasmania, showing the location of all field sites. Filled circles indicate the presence of Cyathea cunninghamii. 


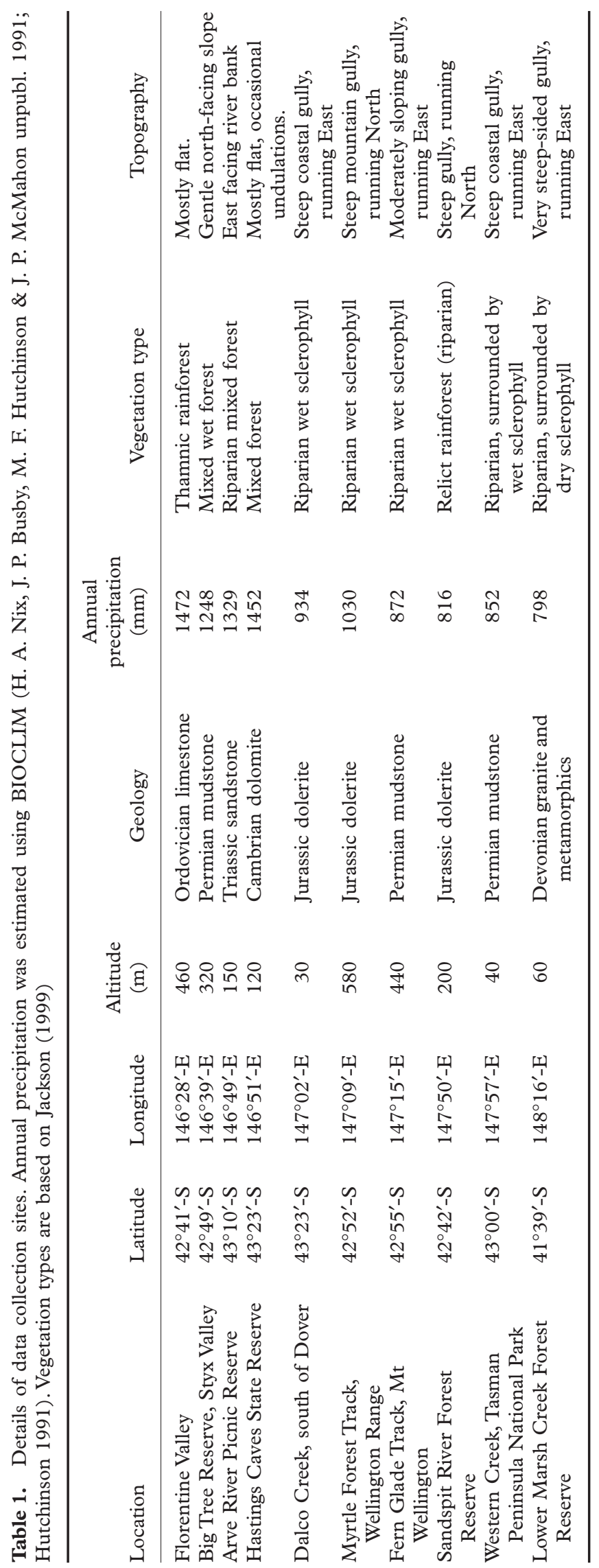




\section{Data collection}

At each of the 10 study sites, 12 D. antarctica trunks were examined for epiphytes. Selection of trunks was random except that only live tree-ferns greater than two metres in height were chosen. Shorter ferns often have a 'skirt' of persistent dead fronds around the trunk, creating a dark and dry environment, which is unsuitable for epiphytes (Page \& Brownsey 1986; N. R. Roberts pers. obs. 2002). Ferns leaning on other substrates were also avoided. At sites where C. cunninghamii was present, up to 12 trunks of this species (or as many as available and suitable) were also examined. For each trunk, all fern and bryophyte epiphytes that could be reached (i.e. below about $3 \mathrm{~m}$ ), were recorded, plus any identifiable species that were beyond reach. Epiphyte loads above $3 \mathrm{~m}$ were usually very low.

Trunk water holding capacity was measured for five trunks of each host species at the Dalco Creek field site. Two samples of root-mantle, approximately $2 \mathrm{~cm}^{2}$ in size, were taken from each fern (10 samples of each host species in total), from approximately $30 \mathrm{~cm}$ and $150 \mathrm{~cm}$ height on the trunk. The samples were immersed in tap water for $24 \mathrm{~h}$ followed by complete drainage for a further $20 \mathrm{~h}$ before being weighed. The samples were oven-dried at $60^{\circ} \mathrm{C}$ for $24 \mathrm{~h}$, weighed again, and the water holding capacity was calculated as a percentage of the dry weight.

\section{Species identification}

All but three bryophyte and fern specimens were identified to species level, using Scott and Stone (1976) and Beever et al. (1992) for the mosses, Scott (1985) for hepatics and Duncan and Isaac (1986) for ferns. Revised taxonomic nomenclature was adopted, in accordance with Ratkowsky (1987), McCarthy and Orchard (1998) and Streimann and Klazenga 2002).

Some species identifications were tentative due the paucity of the material, while some thallose liverworts lacking reproductive structures could not be confidently identified. These specimens were excluded from comparative analysis. Fungi, algae, seed plants and categories of lichens (i.e. crustose, foliose, fruticose) were recorded but not identified beyond this taxonomic level. Voucher specimens of all identified species were deposited in the School of Plant Science, University of Tasmania.

\section{Analysis}

To test the significance of host-type and site as factors that may influence epiphytic species richness at the trunk level, per-trunk species richnesses were com- pared with a two-way factorial analysis of variance, with host species and site as factors. This and other statistical analyses used the model fitting procedure of JMP 4 (SAS Institute Inc, Cary, NC, USA), except where noted. Because of uneven sample sizes, the effects of host species on whole site species richnesses were tested with paired $t$-tests after the data were rarefied (see Simberloff 1979) by repeated random subsampling to seven trunks of each host species at each site. Similarly, comparisons of total species richness across all sites were confounded by differences in sample size. To make a more valid comparison, the total diversity on $D$. antarctica was restricted to sites where C. cunninghamii was present, and then rarefied by repeated subsampling to the same number of trunks as C. cunninghamii at each site.

In order to detect patterns of similarity in the epiphyte assemblages between hosts and across sites, a robust ordination procedure, semi-strong hybrid multi-dimensional scaling (SSHMS), was employed. This used Bray Curtis distances of the presence/ absence data for fern and bryophyte species on individual trunks, and was implemented with PATN (Belbin 1994). All D. antarctica and C.cunninghamii trunks were included.

The effects of host type (C. cunninghamii or D. antarctica), site (the sites where both hosts were present), and interaction between host and site on floristic composition were tested with two way factorial analysis of similarity based on Bray-Curtis distances as described above, using NPMANOVA (Anderson 2001; McArdle \& Anderson 2001). Because this program requires balanced designs, two analyses were performed. One was based on a random subsample of seven trunks of each host species at the four sites where both species were present, and the other subsampled 10 trunks of each host species from the three sites where this was possible.

The association of individual epiphytic species with hosts was tested using logistic regression based on pertrunk presence or absence data, with host type and site as effects in the model.

The water holding capacities of the two species as percentages of dry weight were log transformed and compared with a factorial analysis of variance with species and height on the trunk as factors.

\section{RESULTS}

Ninety seven species of fern and bryophyte were recorded from the trunks of $D$. antarctica, and 64 from Cyathea cunninghamii (Table 2). A species list and frequencies of individual species have been published elsewhere (Roberts et al. 2003). Four of the species on C. cunninghamii were not recorded on D. antarctica trunks at any site, whereas 37 species were only 
recorded on $D$. antarctica. On both host species ferns were the least species-rich epiphytic group, and mosses the most species-rich group (Table 2).

Lichens, especially crustose ones, were common on these tree-ferns, especially on D. antarctica. Seed plants, typically seedlings of tree species, were also quite common.

\section{Relative species richness at two scales}

Dicksonia antarctica supported significantly more species than C. cunninghamii at both the site and individual trunk scales (Figs 2,3). However for individual taxonomic groups this trend was only significant for hepatics and ferns at the scale of species per trunk.

Table 2. Species richness of epiphytic ferns and bryophytes on each host species across sites. Values in parenthesis are estimates of the number of species on Dicksonia when the sample size was reduced by rarefaction to the same as for Cyathea

\begin{tabular}{lccc}
\hline \multicolumn{3}{c}{ Dicksonia } \\
& $\begin{array}{l}\text { all sites } \\
(n=120)\end{array}$ & $\begin{array}{l}\text { Cyathea } \\
(n=48)\end{array}$ & $\begin{array}{l}\text { Cyathea } \\
(\mathrm{n}=39)\end{array}$ \\
\hline Ferns & 16 & $15(14.9)$ & 12 \\
Mosses & 43 & $39(36)$ & 31 \\
Hepatics & 38 & $30(28.5)$ & 21 \\
Total & 97 & $84(79.5)$ & 64 \\
\hline
\end{tabular}

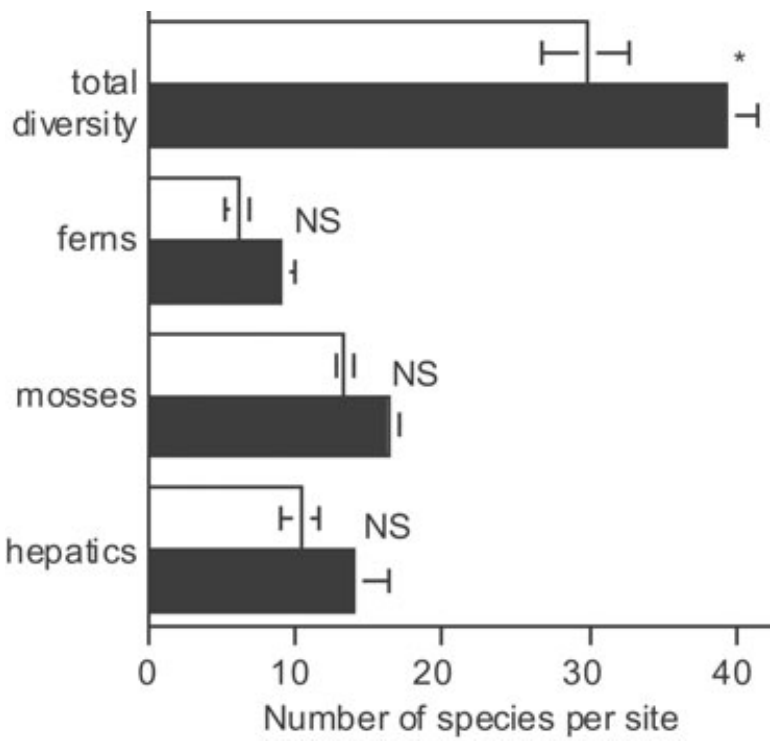

Fig. 2. Mean whole site species richnesses of epiphytes on Cyathea (open bars) and Dicksonia (closed bars), with standard errors, based on seven trunks per species per site. The significance of the difference between hosts (as estimated using paired $t$-tests) is indicated for each group of species (NS $\left.=P>0.05 ;{ }^{\star} P<0.05 ; \star \star P P<0.01\right)$.

\section{Species host preferences}

Ten species showed significant host preferences (Fig. 4). Three ferns (Hymenophyllum flabellatum, Hymenophyllum australe and Grammitis billardierei), two mosses (Rhizogonium novae-hollandiae and Plagiothecium lamprostachys) and two hepatics (Chiloscyphus echinellus and Tylimanthus diversifolius) were recorded significantly more often on $D$. antarctica trunks than on C. cunninghamii trunks. In contrast, two mosses (Hymenodon pilifer and Racopilum cuspidigerum var. convolutaceum) and one liverwort (Radula buccinifera) were more common on C.cunninghamii than on $D$. antarctica. These trends were consistent across all four sites. Hymenodon pilifer was often very conspicuous on C. cunninghamii trunks, covering large areas of the trunk, reaching many metres of height and usually being by far the most abundant species on this host. Similarly, the Hymenophyllum species were often very conspicuous on D. antarctica, but not on C. cunninghamii.

\section{Species assemblages}

The epiphytic assemblages differed highly significantly $(P<0.001)$ between host species and among sites, both when three sites (with 10 replicates) and when four sites (with seven replicates) were analysed

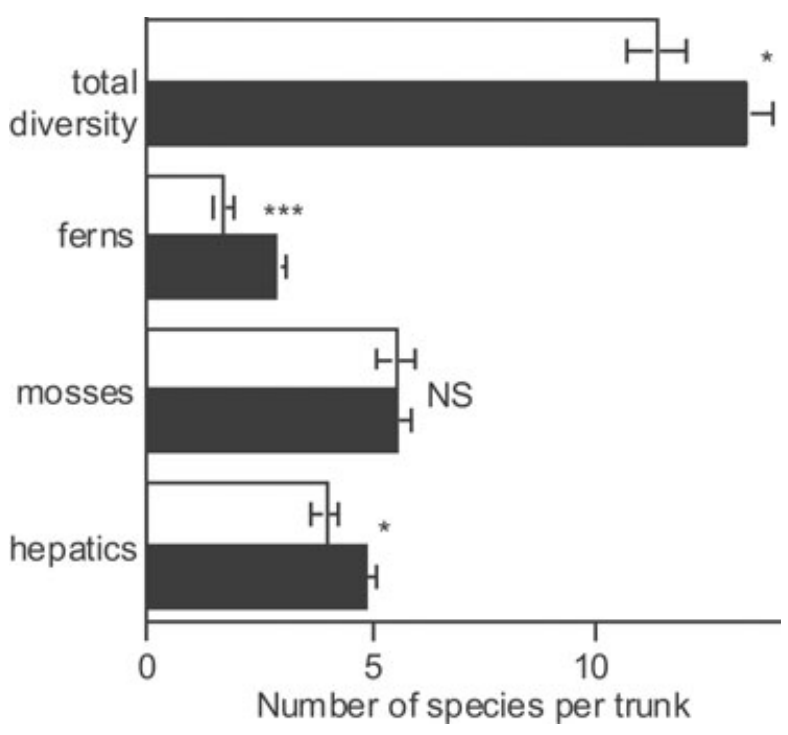

Fig. 3. Site averages of per trunk species richnesses of epiphytes on Cyathea (open bars) and Dicksonia (closed bars), with standard errors. The significance of the difference between hosts (as estimated using two way factorial analysis of variance) is indicated for each group of species (NS $\left.=P>0.05 ;{ }^{\star} P<0.05 ; \star \star \star P P 0.001\right)$. All groups varied very significantly $(P<0.001)$ among sites, but site by host species interactions were not significant $(P>0.05)$. 


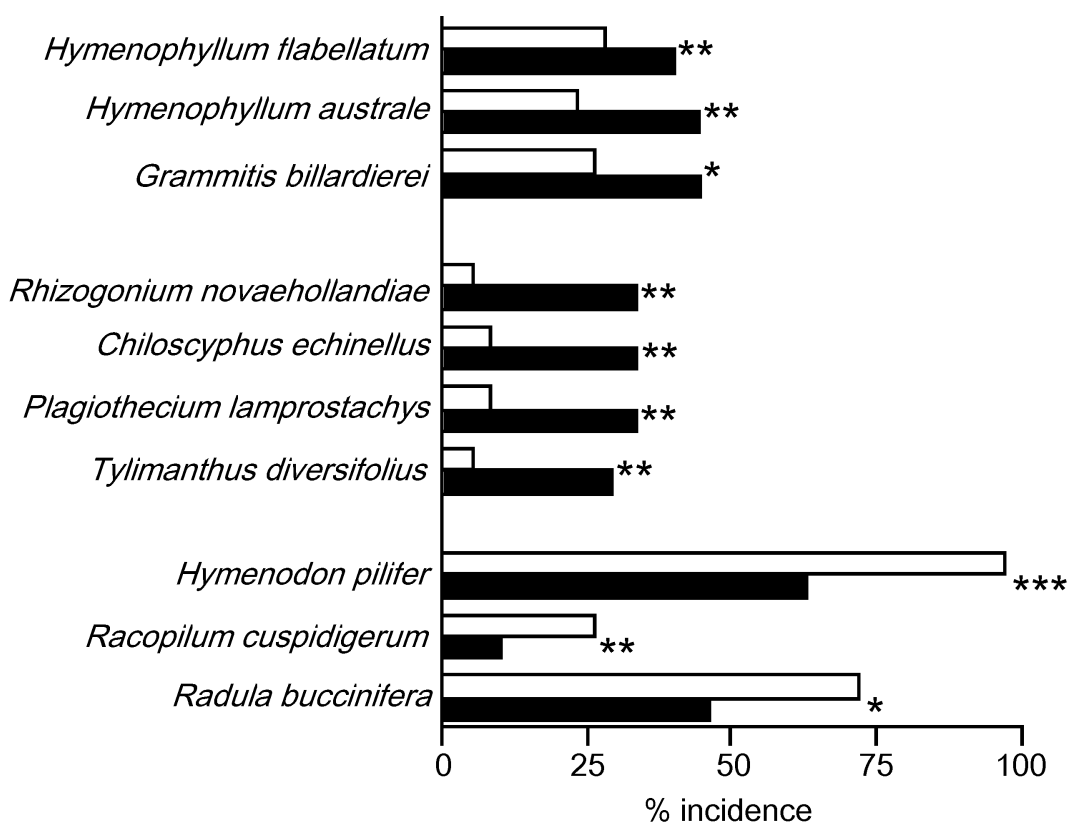

Fig. 4. Percentage incidence on host individuals across four sites of species showing a host preference for either Cyathea (open bars) or Dicksonia (closed bars). The significance of the difference (as estimated using logistic regression) is indicated for each species $\left({ }^{\star} P<0.05 ;{ }^{\star \star} P<0.01 ;{ }^{\star \star}{ }^{\star} P<0.001\right)$. Most of these species also showed significant differences $(P<0.05)$ in abundance across sites.

Table 3. Non-parametric multivariate analysis of variance of floristic composition between host species and sites using 9999 random permutations. Two samples were analysed: one with 10 random trunks per host from three sites, and one with seven random trunks per host from four sites

\begin{tabular}{llcrr}
\hline & \multicolumn{2}{l}{ Four site analysis } & \multicolumn{2}{c}{ Three site analysis } \\
Effect & F & $P$ & F & $P$ \\
\hline site & 5.3 & $\leq 0.0001$ & 11.3 & $\leq 0.0001$ \\
host species & 5.2 & $\leq 0.0001$ & 8.1 & $\leq 0.0001$ \\
site`species & 1.8 & 0.006 & 2.8 & 0.0001 \\
\hline
\end{tabular}

(Table 3). Both analyses showed a significant interaction effect implying that the differences between host species were not the same at all sites. This effect was small compared to the host species and site effects (Table 3), but can be seen in Fig. 5. The host differences have different directions and sizes in the plot of vectors three and four (Fig. 5). Also the assemblages on D. antarctica at sites where C. cunninghamii occurs tend to be at one end of the spectrum for this host (Fig. 5). The assemblages on C. cunninghamii tend to extend further in this same direction.

The average water holding capacity of $D$. antarctica $(1168 \% \pm 127 \%$ [standard error] of oven-dried weight) was significantly $(P<0.01)$ greater than that of C. cunninghamii $(470 \% \pm 56 \%)$. There was no significant difference in water holding capacity between the two heights $(30$ and $150 \mathrm{~cm}$ ), and no significant interaction effect $(P>0.05)$. Differences in water holding capacity between samples of the same host type appeared to correspond to differences in the texture of the adventitious roots.

\section{DISCUSSION}

The 81 bryophyte species on Dicksonia antarctica represent an exceptionally high species richness for a single host species. The 52 bryophyte species on Cyathea cunninghamii is less than would be found on a comparable sample of D. antarctica (approx. 64 species; Table 2), but this is still among the most species rich host-types known for bryophytic epiphytes. In comparison, Dalton (1998a) found 55 bryophyte species on the lower $2 \mathrm{~m}$ of 37 trunks of Nothofagus cunninghamii from 12 sites in western Tasmania, Mazimpaka and Lara (1995) identified 52 bryophytes on Quercus pyrenaica in Mediterranean deciduous woodland in Spain, and Franks and Bergstrom (2000) found 43 species on 25 trunks of Nothofagus moorei in southeastern Queensland. Beever (1984) recorded 32 moss species on Cyathea medullaris in New Zealand compared to 43 species recorded in this study on D. antarctica. However, Beever (1984) sampled less than half as many trunks as this study and did not count hepatics. Thus, this New Zealand tree-fern may host at least as many bryophytes as the Tasmanian tree-ferns. 

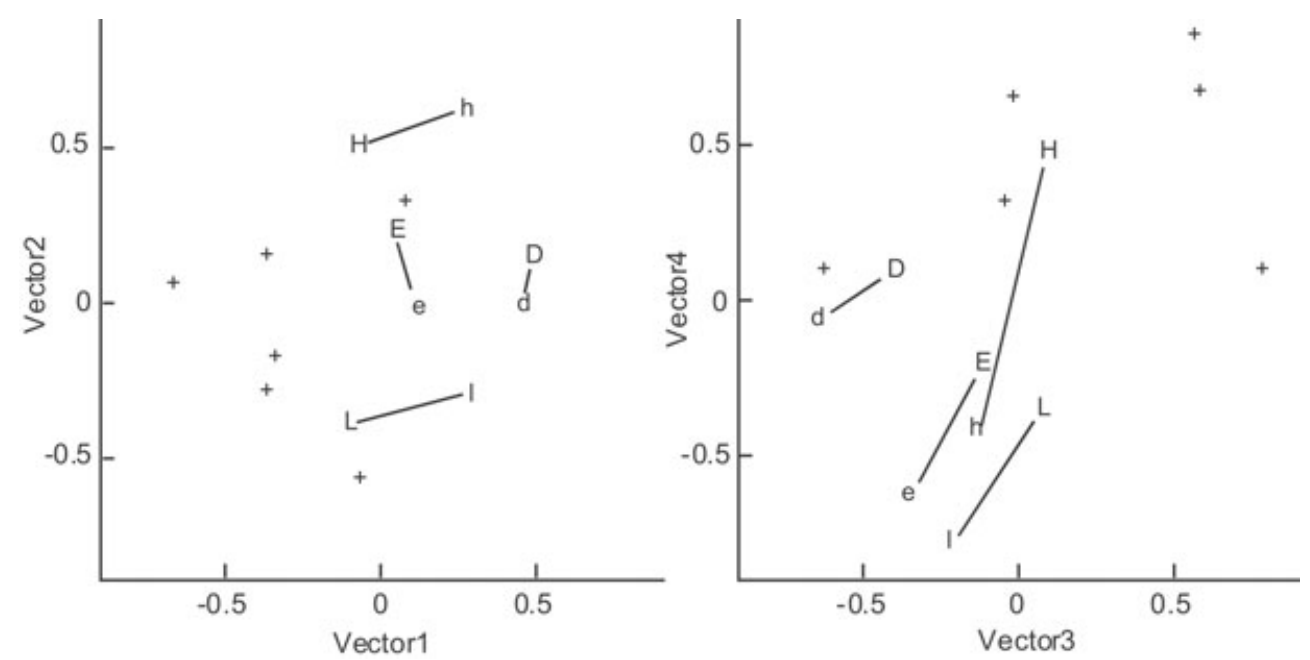

Fig. 5. Ordination plots based on a four dimensional semi strong hybrid multidimensional scaling of tree-fern trunk epiphyte assemblages. Capital and small case letters indicate the mean scores for assemblages on Dicksonia and Cyathea trunks, respectively. Assemblages on Dicksonia populations where Cyathea is absent are also shown (+). Standard errors for the site means on each vector ranged from 0.04 to 0.17 , with no systematic pattern among groups.

Ferns are common and conspicuous epiphytes on D. antarctica, and to a lesser extent, C. cunninghamii. The relatively fewer fern species than bryophyte species does not imply that tree-ferns are poor hosts for ferns, but that bryophyte species vastly outnumber ferns in Tasmanian temperate forests (Dalton 1998b). In fact, epiphytic ferns are often abundant, and almost all of the typically epiphytic ferns occurring in Tasmania were on these tree-fern hosts. Several fern species show strong preferences for tree-fern trunks (e.g. Hymenophyllaceae and Tmesipteris spp.; Garrett 1996). Of these species, only Tmesipteris obliqua and Hymenophyllum rarum were not found on C. cunninghamii as well as D. antarctica in this study, possibly due only to insufficient sample size. Two species more typical of terrestrial environments (Blechnum nudum and Polystichum proliferum) were also found on D. antarctica trunks, suggesting the soft and fibrous root mantle of this species is suitable for the establishment of non-specialist species. Non-epiphytic seed plants (e.g. Coprosma quadrifida, Pimelea drupacea, Pittosporum bicolor and Atherosperma moschatum) were also frequently observed on this host.

Although not identified to species level, lichens were common and may contribute significantly to the epiphytic diversity on tree-ferns. Ford and Gibson (2000) found 25 lichen species growing on D. antarctica trunks in three rainforest sites in Victoria. They concluded that, although $D$. antarctica trunks generally make poorer hosts for lichens than other rainforest hosts such as Nothofagus cunninghamii, they nonetheless provide an important substrate, and are preferred by a few species.

\section{Comparison of the two tree-fern hosts}

At the trunk level, diversity of epiphytes, especially ferns, was significantly higher on $D$. antarctica than on Cyathea cunninghamii. Ferns are likely to be more dependent on their substrate for water and nutrients because they are endohydric, whereas bryophytes are primarily ectohydric in their water conduction. Substrate depth and water holding ability, both which apparently differ between the two tree-fern species, may therefore be important in defining habitat suitability for fern epiphytes.

At the site level, the difference between average diversity of the two hosts was even stronger, but the difference in diversity of fern epiphytes was not significant, indicating a high variation in fern species on C. cunninghamii from trunk to trunk within each site. These fern epiphytes are probably either $D$. antarctica specialists or generalist species, establishing only infrequently and opportunistically on C. cunninghamii trunks.

A few species were completely absent from one of the two hosts, but it was unclear whether these species were displaying actual host preference because they were also rare on the other host. Some of the more common species showed relative preferences for one host over the other, despite not being exclusive to this host. The three fern species that had significant preferences (Hymenophyllum flabellatum, Hymenophyllum australe and Grammitis billardierei) favoured D. antarctica trunks (Fig. 4), which was consistent with the higher fern diversity per trunk on this host. However, despite the greater bryophyte diversity on 
D. antarctica, two mosses and one hepatic displayed significant host preferences for C.cunninghamii. In fact, the strongest epiphyte-host association in this study was that of the moss Hymenodon pilifer for C. cunninghamii.

Dicksonia antarctica and C. cunninghamii supported significantly different epiphytic assemblages to each other within sites, and furthermore, assemblages differed significantly among sites for both hosts (Table 3). Thus host-type may not have been the most important determinant of epiphytic habitat. In both cases the factors relevant in defining habitat were not obvious. Substrate features seemed the most apparent difference between the hosts, whereas meso- and micro- climatic differences were likely to account for much of the variation between sites. Disturbance history, the availability of other substrates, animal interactions, and dispersal limitations could also have affected the distribution of species. Data are scarce or lacking concerning the influence of these site factors on epiphyte assemblages in Australia. However, an exception is Turner (2003) who found, in addition to host differences, that the bryophyte assemblages of some substrates differed significantly among forests of different ages in Tasmania.

The presence of a highly significant interaction effect between host species and site (Table 3, most apparent in plot of vectors 3 and 4 in Fig. 5) implied that the differences between hosts were site dependent. The assemblages on D. antarctica at sites where C. cunninghamii was also present were loosely clustered at one side of the ordination space, and assemblages on C.cunninghamii trunks tended to be located even further in that direction. This trend may reflect an environmental vector across the ordination space. This may be moisture availability, because the sites containing C. cunninghamii tended to be in lower rainfall areas than sites where $D$. antarctica occurred alone. Also the trunks of C.cunninghamii have a much lower water holding capacity than $D$. antarctica, apparently due to a less developed, coarser and less fibrous root-mantle.

\section{ACKNOWLEDGEMENTS}

This research was conducted with in-kind support from the Tasmanian Forest Practices Board. The authors would like to thank Mark Wapstra, Perpetua Turner and two anonymous referees for comments on the manuscript and James Bennett and Erica Williams for field assistance.

\section{REFERENCES}

Anderson M. J. (2001) A new method for non-parametric multivariate analysis of variance. Austral Ecol. 26, 32-46.
Ashton D. H. (1986) Ecology of bryophytic communities in mature Eucalyptus regnans F.Muell. forest at Wallaby Creek, Victoria. Aust. F. Bot. 34, 107-29.

Beever J. E. (1984) Moss epiphytes of tree-ferns in a warm temperate forest, New Zealand. F. Hattori Bot. Lab 56, 8995.

Beever J., Allison K. W., Child J. (1992) The Mosses of New Zealand. University of Otago Press, Dunedin.

Belbin L. (1994) PATN Pattern Analysis Package. Technical Reference. Division of Wildlife and Ecology, CSIRO, Canberra.

Busby J. R. \& Brown M. J. (1994) Southern Rainforests. In: Australian Vegetation. (ed. R. H. Groves) pp. 131-56. Cambridge University Press, Melbourne.

Dalton P. J. (1998a) Ecological Studies on Tasmanian Bryophyta. Masters Thesis, University of Tasmania, Hobart.

Dalton P. J. (1998b) New locality records for some rare mosses in Tasmania. Pap. Proc. Roy. Soc. Tas. 132, 41-5.

DPIWE (2001) Tree-fern Management Plan for the Harvesting, Transporting or Trading of Dicksonia Antarctica in Tasmania. Tasmanian Department of Primary Industries, Water and Environment, Hobart.

Duncan B. D. \& Isaac G. (1986) Ferns and Allied Plants of Victoria, Tasmania and South Australia. Melbourne University Press, Melbourne.

Ford S. \& Gibson M. (2000) Lichens of the soft tree-fern Dicksonia antarctica Labill. in Victorian rainforests. Vic. Natur. 117, 172-9.

Franks A. J. \& Bergstrom D. M. (2000) Corticolous bryophytes in microphyll fern forests of south-east Queensland: distribution on Antarctic beech (Nothofagus moorei). Austral Ecol. 25, 386-93.

Garrett M. (1996) The Ferns of Tasmania: Their Ecology and Distribution. Tasmanian Forest Research Council Inc, Hobart.

Hassall D. C. \& Kirkpatrick J. B. (1985) The diagnostic value and host relationships of the dependent synusia in the forests of mouth Korobaba, Fiji. NZ 7. Bot. 23, 47-54.

Heatwole H. (1993) Distribution of epiphytes on trunks of the arborescent fern, Blechnum palmiforme, at Gough Island, south Atlantic. Selbyana 14, 46-58.

Hutchinson M. F. (1991) The application of thin-plate smoothing splines to continent-wide data assimilation. BMRC Research Report No. 27, pp. 104-13. Bureau of Meteorology, Melbourne.

Jackson W. D. (1999) Vegetation types. In: Vegetation of Tasmania (eds J. B. Reid, R. S. Hill, M. J. Brown \& M. J. Hovenden) pp. 1-10. Australian Biological Resources Study, Canberra.

Jarman S. J. \& Kantvilas G. (1994) Lichens and bryophytes of the Tasmanian World Heritage Area. II. Three forest sites at Pelion Plains. Tasforests 6, 103-20.

Mazimpaka V. \& Lara F. (1995) Corticolous bryophytes of Quercus pyrenaica forests from Gredos Mountains (Spain): vertical distribution and affinity for epiphytic habitats. Nova Hedwigia 61, 431-46.

McArdle B. H. \& Anderson M. J. (2001) Fitting multivariate models to community data: a comment on distance-based redundancy analysis. Ecology 82, 290-7.

McCarthy P. M. \& Orchard A. E. (1998) Flora of Australia, volume 48: Ferns, Gymnosperms and Allied Groups. ABRS/ CSIRO, Canberra.

Medeiros A. C., Loope L. L., Anderson S. J. (1993) Differential colonization by epiphytes on native (Cibotium spp.) and alien (Cyathea cooperi) tree ferns in a Hawaiian rain forest. Selbyana 14, 71-4. 
Moran R. C., Klimas S., Carlsen M. (2003) Low-trunk epiphytic ferns on tree-ferns versus angiosperms in Costa Rica. Biotropica 35, 48-56.

Ough K. \& Murphy A. (1996) The effect of clearfell logging on tree-ferns in Victorian wet forest. Aust. For. 59, 178-88.

Page C. N. \& Brownsey P. J. (1986) Tree-fern skirts: a defence against climbers and large epiphytes. F. Ecol. 74, 787-97.

Pharo E. J. \& Beattie A. J. (2002) The association between substrate variability and bryophyte and lichen diversity in eastern Australian forests. Bryologist 105, 11-26.

Pharo E. J. \& Blanks P. A. M. (2000) Managing a neglected component of biodiversity: a study of bryophyte diversity in production forests of Tasmania's northeast. Aust. For. 63, 128-35.

Piippo S. (1982) Epiphytic bryophytes as climatic indicators in Eastern Fennoscanida. Acta Bot. Fenn. 119, 1-39.

Pócs T. (1982) Tropical forest bryophytes. In: Bryophyte Ecology (ed. A. J. E. Smith) pp. 59-104. Chapman \& Hall, London.

Ratkowsky D. A. (1987) Checklist of the Tasmanian Liverworts. Pap. Proc. Roy. Soc. Tas. 121, 153-8.

Roberts N. R., Dalton P. J., Jordan G. J. (2003) A species list for the bryophytes and ferns occurring as epiphytes on Tasmanian tree ferns. Hikobia 14, 25-31.
Scott G. A. M. (1970) Vegetation studies on Secretary Island, Fiordland: part 11. Epiphytic and ground cryptogamic vegetation on the northern slopes. NZ F. Bot. 8, 30-50.

Scott G. A. M. (1985) Southern Australian Liverworts. Australian Flora and Fauna Series No 2. Australian Government Publishing Service, Canberra.

Scott G. A. M. \& Stone I. G. (1976) The Mosses of Southern Australia. Academic Press, London.

Simberloff D. (1979) Rarefaction as a distribution-free method of expressing and estimating diversity. In: Ecological Diversity in Theory and Practice (eds J. F. Grassle, G. P. Patil, W. Smith \& C. Taillie) pp. 159-76. International Co-operative Publishing House, Fairland, MD.

Slack N. G. (1976) Host specificity of bryophytic epiphytes in eastern North America. F. Hattori Bot. Lab. 41, 107-32.

Streimann H. \& Klazenga N. (2002) Catalogue of Australian Mosses. Flora of Australia Supplementary Series No. 17. Australian Biological Resources Study, Canberra.

Turner P. A. M. (2003) The ecology and conservation of bryophytes in Tasmanian wet eucalypt forest. Unpublished $\mathrm{PhD}$ Thesis. Department of Geography and Environmental Studies, University of Tasmania, Hobart.

Wolf J. H. D. (1994) Factors controlling the distribution of vascular and non-vascular epiphytes in the northern Andes. Vegetatio 112, 15-28. 